\title{
Treatment of Acute Pancreatitis with Trasylol: Report of a Controlled Therapeutic Trial
}

\author{
A. SKYRING,* M.B., B.S., M.R.A.C.P. ; A. SINGER, $†$ M.B., B.S.; P. TORNYA, $\ddagger$ M.B., B.s.
}

Brit. med. F., 1965, 2, 627-629

Acute pancreatitis is a serious disease with a high mortality. The application of general medical and surgical measures such as intestinal decompression and the correction of dehydration and electrolyte imbalance has reduced this mortality significantly, but more specific therapeutic measures are needed. The most widely accepted theory for the causation of acute pancreatitis at the present time is the activation of pancreatic trypsinogen with digestion of the pancreas (Forell, 1962), and the subsequent activation of potent circulatory enzymes, kallikrein and bradykinin, which may account for the severe clinical states found (Thal et al., 1963 ; Forell, 1963). If this theory is correct the possession of a potent non-toxic trypsin and kallikrein inhibitor should assist greatly in the management of this disease. Such an inhibitor was isolated from the parotid gland of cattle by Frey et al. (1950), and is now marketed as Trasylol, a polypeptide of low molecular weight capable of intravenous or intraperitoneal administration with few sideeffects. This drug has potent antitryptic activity in vitro (Moshal et al., 1963), and has been shown to be capable of preventing the development of experimentally induced pancreatitis in animals (McHardy et al., 1963 ; McCutcheon, 1963, 1964). However, despite widespread use in acute pancreatitis in humans it is still not possible to determine its value in the treatment of this disease, as most reports have been of uncontrolled clinical observations (Maurer, 1961 ; Forell, 1963 ; McHardy et al., 1963 ; Moshal et al., 1963).

The only report of a double-blind study is a sentence in a review by Nardi (1963) that he found the drug of no benefit in such a trial, but that his figures were too small for statistical analysis.

The purpose of this paper is to report a double-blind study of the use of this drug in acute pancreatitis of all degrees of severity treated in other respects by the usual therapeutic measures.

\section{Materials and Methods}

All patients admitted to Royal Prince Alfred Hospital with a provisional diagnosis of acute pancreatitis were included in the trial. The diagnosis was confirmed by elevated serum amylase levels (>600 Somogyi units $/ 100 \mathrm{ml}$.), plain $x$-ray film of the abdomen (to exclude gastro-intestinal rupture), and in two cases by laparotomy.

Patients with acute pancreatitis were allotted in random order to treatment with either Trasylol or a placebo (normal saline). All ampoules were identical in every respect, so that the identity of the administered substance was unknown to all persons connected with the trial until after its conclusion.

All patients were treated with intravenous therapy and intragastric suction, as well as general supportive and replacement therapy such as intravenous albumin, calcium, antibiotics, and anticholinergics. The use of these agents was standardized as much as possible.

\footnotetext{
- Directer, the A. W. Morrow Department of Gastroenterology, Royal Prince Alfred Hospital, Sydney, Australia. Supported by a grant from the Bushell Trust.

†egistrar, Royal Prince Alfred Hospital, Sydney, Australia.
† Registrar, Royal Prince Alfred Hospital, Sydney, Australia.
}

In every case an initial loading dose of the "drug" was given intravenously and followed by continuous intravenous infusion over a number of days. As the trial progressed the amount given was increased, as overseas experience suggested that higher doses could be more beneficial. Some of the small doses (see Table II) were due to the early death of the patient.

Classification.-The cases were divided into three types according to the severity of presenting symptoms and signs. Type 1 corresponded to an acute haemorrhagic pancreatitis with features such as shock, dehydration, severe abdominal pain, abdominal tenderness, and serum amylase values usually above 3,000 Somogyi units. At the other end of the scale type 3 was of mild to moderate severity, and corresponded to an oedematous pancreatitis.

Assessment of Cases.-Each patient in the trial was seen by one of us at least twice daily, special attention being paid to abdominal pain, intestinal motility, pulse, temperature, bloodpressure, abdominal distension, rigidity, and tenderness. At the conclusion of the trial and before the code was broken every patient's clinical course was carefully analysed, and each was assigned to one of four groups of responses:

Group A.-Some response to initial dose. Definite clinical improvement in 24 hours. Requiring intragastric suction and intravenous fluids for less than 48 hours. No complications on therapy.

Group B.-No response to initial dose. Clinical improvement in 24 to 48 hours. Requiring intragastric suction and intravenous fluids for less than five days.

Group C.-Poor response to treatment but eventual recovery. No clinical improvement in first 48 hours. Requiring intragastric suction and intravenous fluids for more than five days.

Group D.-Death.

\section{Results}

There were 23 episodes of acute pancreatitis treated in 20 patients ( 9 males and 11 females). The average age of the Trasylol patients was 60 , and those treated with placebo 51 . There were five deaths-three in the Trasylol group and two in the control group (Table I).

\begin{tabular}{|c|c|c|c|c|c|c|}
\hline & & Group A & Group B & Group C & Group D & Total \\
\hline $\begin{array}{l}\text { Trasylol } \\
\text { Placebo .. }\end{array}$ & $\because$ & $\begin{array}{l}0 \\
5\end{array}$ & $\begin{array}{l}6 \\
4\end{array}$ & $\begin{array}{l}2 \\
1\end{array}$ & $\begin{array}{l}3 \\
2\end{array}$ & $\begin{array}{l}11 \\
12\end{array}$ \\
\hline
\end{tabular}

The overall results of the trial (Table I) clearly show that the Trasylol group fared worse than the controls. Table II shows the results when the patients are classified according to severity of disease. Unfortunately, the patients fell unevenly into the two treatment groups, but in all grades of severity the placebo-treated fared equally as well as the Trasylol-treated, and indeed may be regarded as having done better, for in no instance was an A response gained by Trasylol. Table III shows the results when types 1 and 2 are combined.

To determine whether delay in starting treatment could have contributed to the results we compare response with such delay 
(Table IV). Three of the deaths occurred in patients not treated for 24 hours, but in general the Trasylol-treated fared worse in all groups. Table V shows the breakdown according to age. Four of the five deaths occurred in the over-60 agegroup, where unfortunately by chance the Trasylol patients predominate.

\begin{tabular}{|c|c|c|c|c|c|c|}
\hline $\begin{array}{l}\text { Trial } \\
\text { No. }\end{array}$ & $\begin{array}{l}\text { Sex } \\
\text { and } \\
\text { Age }\end{array}$ & Drug Given & Aetiology & $\begin{array}{c}\text { Time from } \\
\text { Onset to } \\
\text { Treatment } \\
\text { (Hours) }\end{array}$ & $\begin{array}{c}\text { Response } \\
\text { and Time } \\
\text { Treatment } \\
\text { to Death }\end{array}$ & $\begin{array}{c}\text { Amount } \\
\text { of Drug } \\
\text { Given } \\
\text { (Units) }\end{array}$ \\
\hline \multicolumn{7}{|c|}{ Acute Haemorrhagic Pancreatitis (Type 1) } \\
\hline 1 & M 43 & Normal saline & Alcoholism & 18 & & - \\
\hline 3 & F 73 & Trasylol & $\begin{array}{c}\text { Gall-bladder } \\
\text { disease }\end{array}$ & 15 & $\begin{array}{c}\text { (9 days) } \\
\text { D } \\
\text { (19 hours) }\end{array}$ & 20,000 \\
\hline $\begin{array}{l}7 \\
8\end{array}$ & $\begin{array}{l}\text { F } 52 \\
\text { F } 87\end{array}$ & "' & " & $\begin{array}{l}72 \\
27\end{array}$ & $\stackrel{\mathrm{C}}{\mathrm{D}}$ & $\begin{array}{r}250,000 \\
75,000\end{array}$ \\
\hline $\begin{array}{l}17 \\
21\end{array}$ & $\mid \begin{array}{ll}F & 49 \\
M & 80\end{array}$ & $"$ & $\mid \begin{array}{l}\text { Alcoholism } \\
\begin{array}{l}\text { all-bladder } \\
\text { disease }\end{array}\end{array}$ & $\begin{array}{l}19 \\
30\end{array}$ & $\begin{array}{l}\text { (24 nours) } \\
\text { B } \\
\text { ( } 9 \text { days) }\end{array}$ & $\begin{array}{l}250,000 \\
325,000\end{array}$ \\
\hline \multicolumn{7}{|c|}{ Moderate to Severe Pancreatitis (Type 2) } \\
\hline 6 & F 51 & Normal saline & $\begin{array}{c}\text { Gall-bladder ! } \\
\text { disease }\end{array}$ & 9 & C & - \\
\hline $\begin{array}{r}9 \\
11\end{array}$ & $\begin{array}{l}M \\
M\end{array} 71$ & $"$ & Alcoholism & $\begin{array}{r}8 \\
120\end{array}$ & $\stackrel{\mathrm{B}}{\mathrm{D}}$ & $=$ \\
\hline $\begin{array}{l}12 \\
14 \\
15 \\
16 \\
22 \\
23\end{array}$ & $\begin{array}{ll}F & 41 \\
M & 56 \\
F & 41 \\
M & 56 \\
F & 71 \\
F & 41\end{array}$ & $\begin{array}{l}\text { Trasylol } \\
\text { Normal saline } \\
\text { Trasylol } \\
\text { Normal saline } \\
\text { Trasylol } \\
\text { Normal saline }\end{array}$ & $\begin{array}{l}\text { Alcoholism } \\
\text { Alcoholism } \\
\text { Alcoholism }\end{array}$ & $\begin{array}{r}5 \\
8 \\
16 \\
38 \\
48 \\
7\end{array}$ & $\begin{array}{l}\text { B } \\
\text { A } \\
\text { B } \\
\text { A } \\
\text { B } \\
\text { B }\end{array}$ & $\begin{array}{l}250,000 \\
225,000 \\
-\overline{-0} \\
420,000\end{array}$ \\
\hline \multicolumn{7}{|c|}{ Mild to Moderate Pancreatitis (Type 3) } \\
\hline $\begin{array}{l}2 \\
4 \\
5\end{array}$ & $\left|\begin{array}{ll}M & 41 \\
M & 38 \\
F & 81\end{array}\right|$ & $\begin{array}{l}\text { Normal saline } \\
\text { Trasylol } \\
"\end{array}$ & 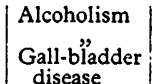 & \begin{tabular}{r|}
60 \\
12 \\
9
\end{tabular} & $\begin{array}{l}\text { B } \\
B \\
B\end{array}$ & $\begin{array}{r}\overline{75,000} \\
200,000\end{array}$ \\
\hline $\begin{array}{l}10 \\
13 \\
18 \\
19 \\
20\end{array}$ & $\begin{array}{ll}\mathrm{F} & 63 \\
\mathrm{M} & 28 \\
\mathrm{~F} & 51 \\
\mathrm{M} & 39 \\
\mathrm{~F} & 58\end{array}$ & $\begin{array}{l}\text { Normal saline } \\
\text { Trasylol } \\
\text { Normal saline } \\
\text { ", }\end{array}$ & $\begin{array}{l}\text { Alcoholism } \\
\text { Alcoholism } \\
\text { Gall-bladder } \\
\text { disease }\end{array}$ & $\begin{array}{l}30 \\
45 \\
24 \\
26 \\
22\end{array}$ & $\begin{array}{l}\stackrel{A}{A} \\
\text { C } \\
\text { A } \\
\text { A }\end{array}$ & $\begin{array}{c}\overline{-} \\
37 \overline{5,000} \\
\overline{-}\end{array}$ \\
\hline
\end{tabular}

TABLE III.-Combined Moderate to Severe Pancreatitis (Types 1 and 2

\begin{tabular}{l|c|c|c|c|c} 
& \multicolumn{7}{|c}{ Combined } \\
\hline & A & B & C & D & Total \\
\hline Trasylol.. & 0 & 4 & 1 & 3 & 8 \\
Normal saline.. & 2 & 2 & 1 & 2 & 7 \\
\hline
\end{tabular}

TABLE IV.-Time from Onset to Treatment in Relation to Later

\begin{tabular}{|c|c|c|c|c|c|c|}
\hline \multirow{2}{*}{ Group } & \multicolumn{2}{|c|}{ Under 12 Hours } & \multicolumn{2}{|c|}{ 12-24 Hours } & \multicolumn{2}{|c|}{ Over 24 Hours } \\
\hline & Placebo & Trasylol & Placebo & Trasylol & Placebo & Trasylol \\
\hline $\begin{array}{l}\mathrm{A} \\
\mathrm{B} \\
\mathrm{C} \\
\mathrm{D}\end{array}$ & $\begin{array}{l}1 \\
2 \\
1 \\
-\end{array}$ & $\begin{array}{l}\overline{3} \\
\overline{-}\end{array}$ & $\frac{1}{1}$ & $\begin{array}{l}\overline{2} \\
0 \\
1\end{array}$ & $\begin{array}{l}3 \\
\frac{3}{1} \\
1\end{array}$ & $\begin{array}{l}\overline{1} \\
\frac{2}{2}\end{array}$ \\
\hline
\end{tabular}

\begin{tabular}{c|c|c|c|c|c|c}
\multicolumn{9}{c}{ TABLE V.-Age in Relation to Subsequent Fate } \\
\hline \multirow{2}{*}{ Group } & Under 45 Years & \multicolumn{2}{c}{45 to 60 Years } & Over 60 Years \\
\hline & Placebo & Trasylol & Placebo & Trasylol & Placebo & Trasylol \\
\hline A & 1 & - & 3 & - & 1 & - \\
B & 3 & 3 & - & $\frac{1}{2}$ & $\frac{1}{2}$ & $\overline{3}$ \\
D & -1 & - & - & - & 1 & 3 \\
\hline
\end{tabular}

\section{Discussion}

The overall results of this study fail to show any beneficial effect of Trasvlol on the course of acute pancreatitis. Inded, it might be claimed to be a liability, for the Trasylol results are much worse than those of the placebo. The excess of Trasylol-treated patients in the over-60 years and acute haemorrhagic pancreatitis (type 1) groups might explain this picture, but it must be said that Trasylol failed to benefit any group- mild, moderate, or severe, young or old, early or late treatment -and no matter how the cases are divided the same result appears. The failure to gain a single $A$ result, manifest by response to the initial dose, clinical improvement in 24 hours, and ability to discontinue intravenous therapy in 48 hours, in the Trasylol group is particularly disturbing, for even in the mild-to-moderate group Trasylol failed to achieve an $\mathbf{A}$ result.

In considering these results it should be noted that Trasylol itself appears to be non-toxic. The $\mathrm{LD}_{50}$ for mice, according to the manufacturer, is 2.5 million kallikrein inhibitor units/ $\mathrm{kg}$., given intravenously. Very large doses (in excess of one million units at a time) have been given to humans without toxic reactions. One of our patients with recurrent pancreatitis developed hypotension and chest pain an hour after an intravenous dose of Trasylol. This may have been a delayed reaction to that drug, but other causes for the pain were not adequately excluded. This patient was again given Trasylol without severe reaction.

It might be claimed that delay in starting treatment may have influenced the results in this trial, for the antitryptic effect of Trasylol would be expected to be of particular benefit in the early stages of the disease before major pancreatic damage had occurred. This hypothesis finds no support in this study (Table IV), for the Trasylol-treated cases on the whole were treated earlier than those on the placebo, and of the three cases treated with Trasylol under 12 hours (only one was over 60) two were in the mild-to-moderate group, and one in the moderate-to-severe group, but still a B result was the best that could be achieved.

It is of interest that a number of the medical officers concerned with treating patients in this trial felt certain they knew whether Trasylol or placebo was being administered in a number of instances because of a dramatic improvement in the patient after the beginning of treatment. In almost every case their judgment was incorrect, and a dramatic response was more often due to the placebo than to Trasylol. In fact, one of the most heartening aspects of this trial was the good response which could be obtained by intensive intravenous therapy with saline, albumin, calcium, and antibiotics combined with intragastric suction. In this trial there were many examples of dramatic relief of pain after the first injection of the "drug" and very rapid clinical improvement over the following 24 to 48 hours. When the results were analysed these events were found to occur with equal frequency in Trasyloland placebo-treated cases, so that one gains the strong impression that an enthusiastic clinical team giving their patients close attention and vigorous therapy will obtain improved results. It follows that a double-blind study is the only way in which a valid assessment of a drug such as Trasvlol can be achieved.

The complete failure of Trasylol to obtain anything approaching the remarkable results obtained in experimental pancreatitis must cast grave doubts on the relevance to human pancreatitis of the experimental models used.

Further, the report by Beck et al. (1964) of failure to recover trypsin from areas of trypsin-induced pancreatitis after 20 minutes must discredit trypsin as a major perpetuating factor in pancreatitis. In this context a trypsin inhibitor such as Trasylol would not be expected to exert any effect. Again, whether this type of pancreatitis has any similarity to human pancreatitis is open to question.

\section{Summary}

The effect of Trasylol (an antitryptic agent: in the treatment of acute pancreatitis of all grades of severity has been assessed in a double-blind study. Twenty-three episodes of pancreatitis were treatid, 11 with Trasylol and 12 with the placebo (normal saline, . Three of the Trasylol-treated and two of the control patients dicd. The response of the surviving patients was 
classified according to their response to the initial dose of the "drug," their general clinical improvement, the duration of intravenous therapy and intragastric suction, and the frequency of complications. Overall results of the trial show that the Trasylol-treated patients did no better than the controls, and indeed may have fared worse. Although more Trasylol-treated patients had severe pancreatitis there was no difference in outcome at any grade of severity. The poor results with Trasylol could not be attributed to delay in starting therapy or to the age of the patient.

We are indebted to Farbenfabriken Bayer A.G., Leverkusen, Germany, who made a gift of Trasylol and the placebo. We would like to acknowledge with gratitude the help of the honorary surgeons of the Royal Prince Albert Hospital who made their patients available for inclusion in the trial. Finally, the study would not have been possible without the co-operation of the nursing and resident staff of the hospital, whose assistance is gratefully acknowledged.

\section{REFERENCES}

Beck, I. T., Kahn, D. S., Solymar, J., McKenna, R. D., and Zylberszac, B. (1964). Gastroenterology, 46, 531.

Forell, M. M. (1962). Germ. med. Mth., 7, 37.

Frey, (1963). Ann. N.Y. Acad. Sci., 104, 368. . 1950). Kallikrein. Enke. Stuttgart.

McCutcheon, A. D. (1963). Ann. Surg., 158, 233.

(1964). Aust. Ann. Med., 13, 174.

McHardy, G., Craighead, C. C., Balart, L., Cradic, H., and La Grange, C. (1963). 7. Amer. med. Ass., 183, 527.

Maurer, G. (1961). Med. Press, 246, 287.

Moshal, M. G., Marks, I. N., Bank, S., and Ford, D. A. (1963). S. Afr. med. $\mathscr{7} ., 37,1072$.

Nardi, G. L. (1963). New Engl. 7. Med., 268, 1065.

Thal, A. P. Kobold, E. E., and Hollenberg, M. J. (1963). Amer. צ. Surg., 105, 708 .

\section{A Further Case of M.C.P.A. Poisoning}

\section{H. R. M. JOHNSON,* M.A., M.B., B.CHIR., M.C.PATH., D.M.J. ; O. KOUMIDES, † B.SC., PH.D., F.R.I.C.}

Brit. med. F., 1965, 2, 629-630

M.C.P.A. (2-methyl-4-chlorophenoxyacetic acid) is one of the recently developed hormone weed-killers and is freely available without control. It is claimed that it has a low toxicity. A search of the literature has revealed only one fatal case (Popham and Davies, 1964). It was felt, therefore, that a further case of fatal poisoning by M.C.P.A. was worth recording.

\section{Case Report}

A retired blacksmith aged 65 was admitted in coma to Joyce Green Hospital, Dartford, at 2 p.m. on 24 July 1964 under the care of Dr. G. B. Stratton. He had a 40-year history of dyspnoea and cough with purulent sputum, and bronchiectasis of the right middle lobe had been diagnosed in 1958. He had had attacks of acute bronchitis and pneumonia on several occasions, the first as far back as 1924 .

In 1955 he developed auricular fibrillation, and had been treated for congestive cardiac failure with digoxin for the seven years prior to his death. He gave up his work as a blacksmith at the age of 61 and worked as a storeman for three years until his retirement in April 1964.

He had become depressed as a result of his increasing incapacity, and in 1955 attempted to take his life by an overdose of sleepingtablets. He was treated successfully and later transferred to a mental hospital for further treatment of his depression. Since his retirement he had remained depressed and his activities had become increasingly curtailed by breathlessness. His hobby was gardening, of which he was very fond, and his family said that "he didn't seem to be able to do his gardening as he used to," and this had aggravated his depression.

He was found unconscious at 12 noon on 24 July, slumped in the toilet, by his son-in-law, who had come to look for him as he had not appeared for lunch. There was an empty 2 -fl. oz. (57-ml.) bottle of Verdone weed-killer on the shelf in the toilet, and later an empty codeine-tablet bottle was found in his bedroom. He was transferred to hospital at 2 p.m. the same day.

On admission he was deeply unconscious and unresponsive to all stimuli. He had pinpoint pupils which did not react to light. $\mathrm{He}$ was sweating, and had a pulse rate of 64 and a blood-pressure of 80/60. Apart from extrasystoles his heart sounds were normal.

\footnotetext{
* Senior Lecturer, Department of Forensic Medicine, the London Hospital Medical College.

t Lecturer, Department of Forensic Medicine, the London Hospital Medical College.
}

There were multiple rhonchi throughout the chest with crepitations at the bases. Examination of the central nervous system showed almost absent reflexes with no asymmetry and extensor plantar responses. All the limbs were flaccid. He was incontinent of urine and facces. A lumbar puncture was not performed.

His stomach was washed out and he was given Methedrine (methylamphetamine hydrochloride) $30 \mathrm{mg}$., hydrocortisone 200 mg., and Lethidrone (nalorphine hydrobromide) $10 \mathrm{mg}$., the latter being repeated at 5 p.m.

By 8.30 p.m. his pulse rate was 92 and his blood-pressure 110/40, but by 1.30 a.m. the following day, $25 \mathrm{July}$, his blood-pressure had fallen to $80 / 60$ and he was not responding to Methedrine. He was sweating profusely, his pulse was weak, and his respirations had become rapid. His chest was sucked out and the hydrocortisone, Lethidrone, and Methedrine were repeated. A saline drip was begun. However, he remained deeply unconscious with a steadily falling blood-pressure, and he died at 8.30 a.m. on $25 \mathrm{July}, 20 \frac{1}{2}$ hours from the time he had been found unconscious.

\section{Necropsy Findings}

Necropsy was performed at 4 p.m. on 27 July. The body was that of a moderately well nourished man, with small blisters on the skin of the inner side of the right knee, right foot, and left shin. The brain was swollen but showed nothing else of note, and the cerebral arteries were free from atheroma. The lungs were bound down by old adhesions. There was congestion and oedema of all lobes, with emphysema of the apices and anterior borders of both lungs. The bronchi were greatly thickened and inflamed and contained pus. Those to the right middle and lower lobes were strikingly dilated and packed together with fibrosis of the lung parenchyma. There was no sign of pneumonia or pulmonary embolism. The heart was enlarged $(380 \mathrm{~g}$.), with hypertrophy and dilatation of the right ventricle and dilatation of the right atrium. The pericardium and myocardium were healthy, the valves were competent, and there was only a mild degree of atheroma of the coronary arteries and aorta. The stomach contained $250 \mathrm{ml}$. of brown fluid. There were no obvious haemorrhages, or corrosion of the mucosa, but there was a chronic benign gastric ulcer $\frac{1}{2}$ in. $(1.3 \mathrm{~cm}$.) in diameter on the lesser curvature. The other organs were intensely congested but were otherwise unremarkable.

An extensive histological examination revealed evidence of severe chronic inflammation in the lungs with emphysema and fibrosis of the parenchyma with much carbon pigment, and thickening of the 